\title{
Extração e Purificação da Cafeína numa Amostra de Chá
}

\author{
Maria João Ferreira ${ }^{1, *}$, Ana Fernandes ${ }^{1}$, Paula GaiO $^{2}$, \\ Paulo Rosa ${ }^{1}$, Nuno Vieira ${ }^{1}$
}

\begin{abstract}
P ropõe-se a extração sólido-líquido da cafeína de uma amostra de $5 \mathrm{~g}$ de folhas de chá finamente cortadas, através do cozimento em água durante sete minutos, e posterior extração líquido-líquido com o solvente diclorometano. A cafeína extraída pode ser purificada por sublimação. Este procedimento permite obter um teor de cafeína suficiente para análise do seu grau de pureza por determinação do seu ponto de fusão. A solução aquosa é mantida alcalina, por adição de carbonato de cálcio, que hidrolisa o sal cafeína-tanino, permitindo aumentar o rendimento na fase de extração líquido-líquido. Estas adaptações aos procedimentos tradicionais permitem otimizar o tempo de execução de modo a ser aplicável nos tempos letivos vigentes no ensino secundário.
\end{abstract}

\section{INTRODUÇÃO}

A cafeína (3,7-dihidro-1,3,7-trimetil-1H-purina-2,6-diona) apresenta-se como a substância constituinte do chá e do café, que os torna bebidas tão apetecidas pelos homens e pelas mulheres nas mais diversas culturas. A cafeína é um composto natural pertencente à família das metilxantinas [1], da classe dos alcaloides, com propriedades básicas. A ingestão destas, extraídas das plantas, é possivelmente uma das práticas mais antigas para estimular o organismo humano. A cafeína, mais especificamente, tem um efeito vasodilatador e diurético, com uma forte capacidade de aumentar a vigilância, inibir o sono e potenciar as capacidades cognitivas, uma vez que reduz a fadiga e estimula o sistema nervoso central [2]. Algumas das fontes vegetais de cafeína mais conhecidas são os grãos de café e de cacau, as folhas de chá e as sementes de cola e guaraná [1]. Mais especificamente, no que respeita às folhas de chá, estas contêm um teor de cafeína entre $2 \%$ e $4 \%$ (Tabela 1), variando consoante a espécie, a localização da folha na planta, o local de cultivo ou mesmo as granulações da amostra [2]. O chá é proveniente das folhas da Camellia sinensis, uma espécie da família Theaceae, originária das florestas húmidas da Ásia e Indonésia. As variedades botânicas, a idade das folhas, o tipo de secagem, a origem

\footnotetext{
${ }^{1}$ Escola Secundária da Amadora, Amadora

2 Escola Secundária Fernando Namora, Brandoa

*E-mail: mariaruaferreira@sapo.pt
}

geográfica, a preparação e acondicionamento das folhas, originam os diferentes tipos de chás comerciais. No entanto, todos estes produtos podem ser divididos em quatro categorias distintas: chá branco (não fermentado, produzido a partir das folhas mais tenras), chá verde (levemente fermentado), chá oolong (com fermentação mediana) e chá preto (bem fermentado e forte) [2].

A ingestão de cafeína pode ocorrer a partir da sua dissolução em água, por infusão das folhas do chá. Estas são constituídas principalmente por celulose e, além da cafeína, contêm pigmentos, clorofilas e taninos. Estes últimos são compostos polihidroxifenólicos de elevada massa molecular, constituídos por polifenóis e glúcidos, entre outros, e com propriedades químicas comuns à cafeína. Dentro deste grupo salientam-se os taninos hidrolisáveis, com uma estrutura que é caracterizada por um poliálcool com um núcleo central (usualmente a $\mathrm{D}$ -glucose), cujos grupos hidroxilos se encontram parcial ou totalmente esterificados por grupos fenólicos [3-5]. Os taninos, e outros agentes aromatizantes dissolvidos, são os responsá-

Tabela 1 - Concentração de cafeína em diversas bebidas comerciais [3]

\begin{tabular}{|l|c|}
\hline \multicolumn{1}{|c|}{ Bebida } & Cafeína $(\mathrm{mg} / \mathrm{mL})$ \\
\hline Café & $80-125$ \\
\hline Café descafeinado & $2-4$ \\
\hline Chá & $30-75$ \\
\hline Leite com cacau & $3-30$ \\
\hline
\end{tabular}

veis pelo sabor característico do chá, enquanto bebida. Note-se, a título de curiosidade, que o café e o chá são rotulados como descafeinados quando é removida $97 \%$ da sua cafeína.

Num processo em laboratório, a cafeína pode ser extraída facilmente do chá por um mecanismo idêntico ao ritual de preparação de uma chávena de chá, levando as folhas à ebulição em água, durante cerca de $7 \mathrm{~min}$. Um período de ebulição superior apenas permitirá que outras substâncias venham a ser dissolvidas, contribuindo para um incremento do teor final de impurezas [3]. Atendendo a que a cafeína é um sólido cristalino, branco e inodoro, a simples observação da solução resultante da ebulição permite inferir que, para além desta, outras substâncias foram dissolvidas.

A cafeína é um alcalóide de fórmula molecular $\mathrm{C}_{8} \mathrm{H}_{10} \mathrm{~N}_{4} \mathrm{O}_{2}$, com a estrutura química que se apresenta na Figura 1. Os alcalóides apresentam um sabor amargo, natural dos compostos azotados encontrados em plantas. A propriedade básica destes elementos

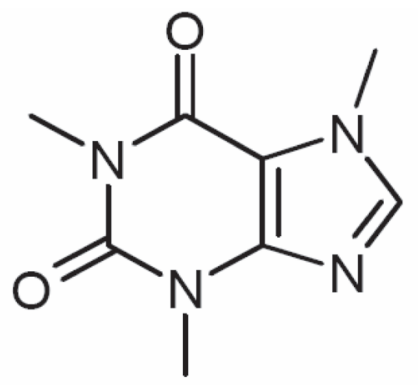

Figura 1 - Estrutura molecular da cafeína 
resulta do par de eletrões não ligantes presente em pelo menos um átomo de azoto, apresentando, frequentemente, uma forte atividade fisiológica sobre o Homem [1], como foi referido. Entre estes elementos podemos encontrar a morfina, a heroína, o ácido lisérgico (LSD), a cocaína, a estricnina, a quinina ou a nicotina.

O azoto básico presente na estrutura molecular destes compostos, e particularmente da cafeína, pode ser usado para aumentar ou diminuir a sua solubilidade em água. Em meio ácido, a cafeína apresenta-se na forma catiónica, dando-se a formação de um sal do ácido conjugado, que lhe confere uma elevada solubilidade em água. Por outro lado, quando a cafeína está presente em meio básico, assume a forma neutra com uma baixa polaridade.

Qualquer processo de extração tem o seu resultado potenciado quando é maximizada a diferença de solubilidade entre as substâncias a separar e os seus interferentes.

Na extração da cafeína das folhas de chá através do cozimento em água, durante 7 minutos, verifica-se a existência de outros compostos igualmente solúveis em água, nomeadamente taninos, clorofilas e flavonoides. Os taninos, compostos polihidroxifenólicos com caráter ácido, de polaridade intermédia, dissolvem-se bem na água a quente e são razoavelmente solúveis em diclorometano (solvente extrator a utilizar na etapa seguinte, extração líquido-líquido), a par da clorofila não decomposta e de outros compostos aromáticos presentes no chá. $A$ adição de carbonato de cálcio (base) à solução aquosa tem um duplo efeito, por um lado permite que a cafeína possa estar presente na sua forma básica, livre, mas apresenta também um efeito adicional. De facto, aumentando o $\mathrm{pH}$ diminui-se a solubilidade em água dos sais de taninos entretanto formados o que permite a sua remoção parcial, por filtração a vácuo, ainda antes da cafeína ser posteriormente extraída com diclorometano na segunda etapa do processo.

Assim, a separação da cafeína dos taninos só é possível por dissolução seletiva, diminuindo a sua solubilida- de em diclorometano. Este efeito consegue-se convertendo os taninos em compostos mais polares, por hidrólise básica da sua função poliéster, por tratamento em carbonato de cálcio. É expectável, atendendo à estrutura química dos taninos, que sob estas condições reacionais se obtenha o respetivo ácido carboxílico na forma de sal e que com este procedimento os taninos sejam transformados em sais insolúveis em água, os quais irão precipitar, mantendo a cafeína em solução.

Em conclusão, apesar da cafeína permanecer solúvel em água, ao manter-se a solução alcalina minimizam-se as perdas da cafeína e maximiza-se a remoção das impurezas [7], o que irá permitir melhorar a eficiência da posterior extração líquido-líquido.

A solubilidade da cafeína em água é de $2,2 \mathrm{mg} / \mathrm{mL}$ a $25^{\circ} \mathrm{C}, 180 \mathrm{mg} / \mathrm{mL}$ a $80^{\circ} \mathrm{C}$, e $670 \mathrm{mg} / \mathrm{mL}$ a $100^{\circ} \mathrm{C}$ sendo, também, bastante solúvel em diclorometano. Quando se procede à extração da solução aquosa acastanhada, resultante da ebulição, com este solvente, extrai-se maioritariamente a cafeína. O extrato diclorometanico daqui resultante contém cafeína com pequenas quantidades de impurezas. A posterior evaporação do solvente permite obter crude de cafeína, de onde, por sublimação, se pode obter cafeína com um grau de pureza relativamente elevado [3].

\section{Procedimento e Resultados}

Pesaram-se 5,005 g de folhas de chá Earl Grey, para um gobelé de $250 \mathrm{~mL}$, ao qual se adicionaram $3,000 \mathrm{~g}$ de carbonato de cálcio e $100 \mathrm{~mL}$ de água destilada. Levou-se à ebulição com agitação durante 7 minutos.

Esta mistura foi transferida para uma ampola de decantação, após arrefecimento à temperatura ambiente e filtração a vácuo. Adicionaram-se-Ihe $25 \mathrm{~mL}$ de diclorometano e, com agitação suave, extraiu-se a cafeína por recolha da fase orgânica (Figura 2). Repetiu-se este procedimento três vezes. É de notar que neste processo de extração com diclorometano, formam-se facilmente emulsões, em resultado da presença de substâncias no chá que geram gotículas (de uma camada orgânica) em suspensão na camada aquosa. Assim, deve-se proceder com o maior cuidado para que esta emulsão não se forme, agitando muito lentamente a solução a ser extraída até se observar a diferenciação das fases, de modo a ser possível separá-las. $\mathrm{O}$ aparecimento de uma pequena quantidade de emulsão pode ser solucionado, deixando a mistura repousar tempo suficiente. Ou, alternativamente, pode-se adicionar cloreto de sódio até quase à saturação, com agitação suave, dado que, como é sabido, facilita-se a separação se a camada aquosa for altamente iónica. No caso de se estarem a tratar pequenas quantidades de mistura, pode-se recorrer a uma centrífuga.

A fase orgânica foi posteriormente lavada com cerca de $20 \mathrm{~mL}$ de água destilada, seguida de nova decantação. Removeu-se toda a água da fase orgânica com recurso a sulfato de magnésio anidro. Após se ter filtrado por gravidade e lavado o resíduo com cerca de $2 \mathrm{~mL}$ de diclorometano, procedeu-se a evaporação do solvente, em evaporador rotativo.

Este procedimento permitiu obter uma massa de crude suficiente para posterior purificação por sublimação, preferencialmente em supressão (Figura 3). Pode-se, ainda, analisar o grau de pureza da cafeína por determinação do seu ponto de fusão. Salienta-se que este método de extração não permite obter um analito puro, mas é suficiente para obter um sólido branco

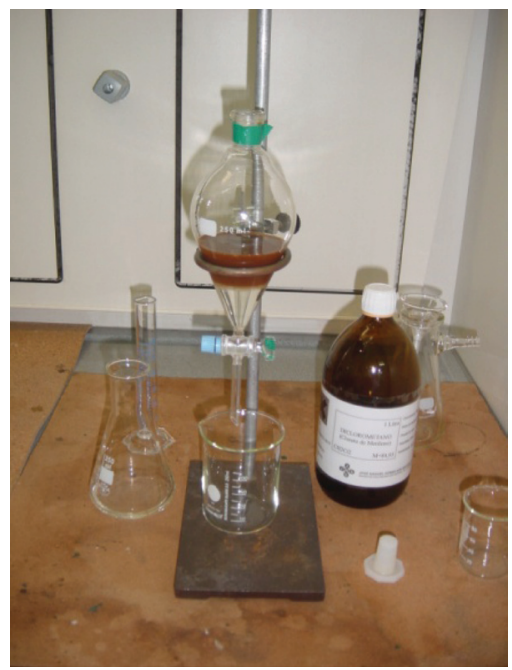

Figura 2 - Extração da cafeína com o solvente diclorometano, sendo visível a existência de uma emulsão 
cristalino com um elevado teor de cafeína (Figura 4), com um ponto de fusão superior a $215^{\circ} \mathrm{C}$, contra os $237^{\circ} \mathrm{C}$ tabelados para a cafeína pura.

\section{Discussão e Conclusões}

Ao longo das últimas três décadas têm sido propostas metodologias para a extração da cafeína das folhas do chá [6], envolvendo a extração deste composto com água a ferver, durante 15 a 20 minutos, e posterior remoção da fase aquosa com recurso a um solvente orgânico, de baixo ponto de ebulição, imiscível em água e que permita a extração seletiva da cafeína, para minimizar o arrastamento simultâneo de interferentes. O solvente eleito é, habitualmente, o clorofórmio. O crude obtido exige sempre uma purificação por sublimação ou por recristalização.

A metodologia apresentada neste artigo não difere substancialmente das demais apresentadas na literatura; pretende, sobretudo, otimizar o processo de modo a torná-lo exequível em atividade escolar do ensino secundário, tendo-se particular atenção ao tempo de execução e à segurança dos operadores. Para isso, otimizaram-se parâmetros, como o tempo de ebulição da amostra, a quantidade de amostra e a opção pelo diclorometano como solvente extrator, de menor toxicidade que $\mathrm{o}$ tradicionalmente proposto, mas igualmente eficiente e seletivo na extração. A cafeína assim obtida apresenta um elevado grau de pureza, sem pôr em risco o rendimento do processo, com um acréscimo da segurança e com redução dos custos ambientais.

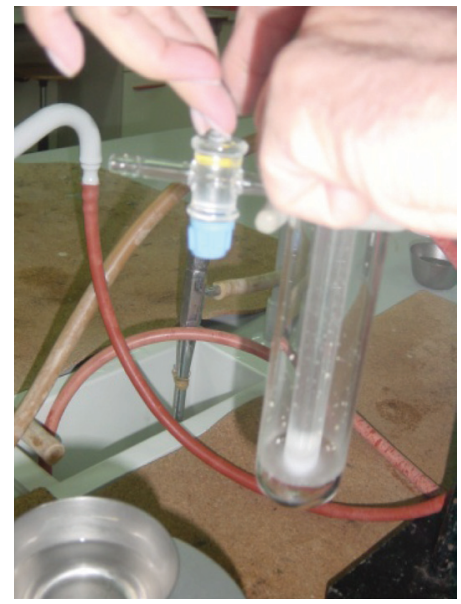

Figura 3 - Purificação do crude por sublimação em supressão
Considerando que o recurso ao diclorometano, no processo de extração líquido-líquido, conduz à formação de emulsões (uma desvantagem relativamente ao clorofórmio), propõe-se uma primeira extração muito suave, girando apenas a ampola de decantação para que a interface entre as fases orgânica e aquosa se apresente bem definida, sendo posteriormente efetuadas mais três extrações, com agitação progressivamente mais vigorosa. Os principais desafios experimentais no isolamento da cafeína prendem-se com dois fatores: a baixa solubilidade da cafeína em água fria, que aumenta significativamente com o aumento da temperatura de extração, e a transferência de outros compostos durante o processo de extração, nomeadamente taninos, flavonoides e clorofilas, os quais, com exceção da celulose, são solúveis em água. A eficácia da separação é melhorada com o tratamento com carbonato de cálcio que, sem alteração significativa da solubilidade da cafeína, baixa significativamente a solubilidade dos interferentes em água tornando-os, consequentemente, removíveis por filtração.

A utilização de diclorometano como solvente extrator permite a remoção de pigmentos flavonóicos, os quais são insolúveis neste solvente, e a consequente obtenção da cafeína na fase orgânica relativamente pura, com uma coloração ligeiramente esverdeada devido a presença de impurezas, como a clorofila. A evaporação do solvente faz-se com recurso a um evaporador rotativo, obtendo-se o crude sólido, ainda de cor esverdeada.

A purificação da cafeína por sublimação, que em subpressão ocorre a aproximadamente $80^{\circ} \mathrm{C}$, permite a obtenção de um produto branco, cristalino, relativamente puro. O ensaio da metodologia aqui proposta permite obter

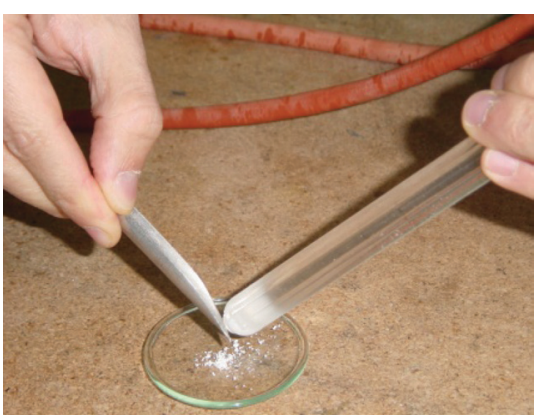

Figura 4 - Obtenção da cafeína pura uma massa de cafeína suficiente para deteção e análise do grau de pureza, por determinação do ponto de fusão.

No processo educativo, o fator tempo é fundamental, decorrente das limitações impostas pelo horário escolar. De facto, apesar da extração da cafeína não constar dos programas curriculares das Ciências de Física e Química, nas diversas vertentes e modalidades de ensino, os processos de separação são objeto de estudo, tanto no ensino regular, como no ensino profissional (sendo, neste último, abordados com algum pormenor na disciplina de Análises Químicas). Neste contexto, optou-se pela sublimação para a purificação da cafeína, uma vez que permite utilizar pequenas quantidades de amostra e é relativamente rápida, preterindo-se outras técnicas alternativas de purificação, como por exemplo a recristalização, por um lado, devido à sua maior morosidade e às perdas inerentes às respetivas etapas, por outro, a um maior número de passos e de material envolvido.

Opções como a redução do tempo de ebulição para 5 a 7 minutos, a utilização de uma pequena quantidade de folhas de chá finamente divididas, $5 \mathrm{~g}$, e a purificação do crude por sublimação, permitem estabelecer uma metodologia viável para ser aplicada em disciplinas do ensino secundário, cujo tempo letivo se estende a $90+45$ min no ensino regular e a $180 \mathrm{~min}$, no ensino profissional.

Esta atividade experimental apresenta, ainda, a vantagem de permitir desenvolver competências atitudinais de concentração e atenção, uma vez que exige o controlo de diferentes variáveis durante todo o processo, permitindo também desenvolver competências de observação e consolidar técnicas de registo organizado de dados e de resultados.

É de referir, ainda, que atividades experimentais como esta se enquadram preferencialmente numa fase de consolidação de conhecimentos, uma vez que envolvem várias técnicas distintas, obrigando a alguma capacidade de organização do trabalho e destreza no manuseamento do material e equipamento. 


\section{AgradeCimentos}

Agradecemos ao CEEQ - Centro de Estudos de Engenharia Química, do Instituto Superior de Engenharia de Lisboa (ISEL), pela cedência das instalações e por todo o apoio técnico e humano disponibilizado.

\section{REFERÊNCIAS}

[1] A. P. Cunha, Farmacognosia e Fitoquímica, Fundação Calouste Gulbenkian, Lisboa, 2005.
[2] A. P. Cunha, A. P. Silva, O. R. Roque, Plantas e Produtos Vegetais em Fitoterapia, $2^{\mathrm{a}}$ ed., Fundação Calouste Gulbenkian, Lisboa, 2006.

[3] Portland Community College, Extraction of Caffeine from Tea Leaves, http:// spot.pcc.edu/ chandy/241/CaffeineExtractionCH2CCl2.pdf, acedido em 22-11-2010, 2010.

[4] Faculdade de Ciências de Lisboa, DQB, Química dos Produtos Naturais, old.dqb. fc.ul.pt/cup/44361/aulas\%202010_11/ (11)QPN_Taninos_10_11.pdf, Ma Eduarda M. Araújo, acedido em 31-03-2011.
[5] C. Pintá, Emprego de Coagulantes Orgânicos Naturais como Alternativa ao Uso de Sulfato de Alumínio no Tratamento de Água, Tese de Projeto, Universidade Federal do Rio Grande do Sul, Porto alegre, Brasil, 2008.

[6] Departamento de Ciências Naturais, ECBS/UNIRIO, Extracção da cafeína, http://www.unirio.br/laqam/Quimica_aplicada/pratica3.pdf, acedido em 22-11-2010, s.d.

[7] S. D. Murray, P. J. Hansen, J. Chem. Ed. 72 (1995) 851-852.

\section{Atualidade Científica}

\section{"Fita cola" química para separar nanotubos}

De acordo com uma equipa internacional de cientistas, é possível separar misturas de nanotubos metálicos e nanotubos semicondutores usando "fita cola" química. Esta técnica simples e barata pode levar a desenvolvimentos futuros em dispositivos nanoeletrónicos.

As características elétricas dos nanotubos de carbono de paredes simples (SWNTs) tornam-nos úteis em nanoeletrónica. No entanto, as tecnologias atuais produzem misturas de SWNTs metálicos (m-SWNTs) e SWNTs semicondutores (s-SWNTs), levando a uma diminuição da performance dos dispositivos.

Recentemente, uma equipa liderada por Jin Zhang da Universidade de Peking, em Pequim, China, desenvolveram equivalentes químicos de fitas cola, que podem aderir a amostras de SWNTs e depois serem descoladas, trazendo com elas m-SWNTs ou s-SWNTs, deixando na amostra o outro tipo de SWNTs.

"O mecanismo de separação é baseado na diferença de interação entre os compostos químicos e os SWNTs com diferentes propriedades elétricas", explica Zhang. Podem ser usados grupos funcionais diferentes para atrair os diferentes SWNTs, separando assim a mistura.

A equipa usou polidimetilsiloxano (PDMS) como material de base para as fitas cola. A este ligaram 3-aminopropil-trietoxisilano para produzir a fita cola A ou trietoxifenilsilano para produzir a fita cola $\mathrm{P}$, introduzindo grupos funcionais amina e fenil, respetivamente. Testando cada fita cola em misturas de s- e m-SWNTs a equipa foi capaz de separar os dois tipos de SWNTs.

"Enquanto a fita cola A remove seletivamente s-SWNTs, a fita cola P adere a m-SWNTs", diz Zhang. "A separação de s- e m-SWNTs usando esta técnica é fácil e barata", acrescenta. Adicionalmente, é possível separar sistemas de SWNTs longos e curtos, sem danificar os nanotubos, o que é um avanço relativamente a outras técnicas.

Andre Geim, da Universidade de Manchester, Reino Unido, que recebeu em 2010 o prémio Nobel da Física pela separação de grafeno - folhas de carbono com a espessura de um átomo - da grafite, usando fita cola convencional, diz: "A abordagem proposta parece não só engraçada, mas também potencialmente muito importante".

"A técnica é significativa, uma vez que a separação ocorre a seco sem destruir os nanotubos", explica Esko Kauppinen, um especialista em nanomateriais da Universidade de Tecnologia de Helsínquia, Finlândia. “No entanto, está ainda por saber se o método funciona com novelos de nanotubos - esta questão é importante, uma vez que os SWNTs formam novelos com facilidade", acrescenta.

Zhang concorda que existe ainda trabalho para ser realizado, mas afirma que o seu método pode ser reproduzido em qualquer laboratório de investigação. "Acredito que a técnica pode promover a separação de SWNTs a uma escala industrial, o que é uma boa notícia para o sector da nanoeletrónica baseada em SWNTs". Kauppinen concorda que o método "pode encontrar aplicações a curto prazo, por exemplo, na produção de sensores baseados em transístores de efeito de campo".

No futuro, a equipa de Zhang espera otimizar a produção das "fitas cola" e testar outros materiais para tornar o processo ainda mais barato.

(adaptado de http://www.rsc.org/chemistryworld/News/2011/June/09061103.asp) 